\title{
Bireyselleştirilmiş Eğitim Programı (BEP) Hazırlama Sürecinde Tercih Edilen BEP Uygulamaları Üzerine Öğretmenlerin Görüşlerinin İncelenmesi
}

\author{
Şerife Şenay İlik*, Yunus Emre Günay***
}

Makale Geliş Tarihi: 28/04/2020

Makale Kabul Tarihi: 24/06/2020

DOI: $10.35675 /$ befdergi. 728139

$\ddot{O} z$

Bu çalışma da amaç, ögrretmenlerin kullandığı Paket Program BEP(PPBEP) ve Öğretmenlerin Hazırladı̆̆ BEP(ÖHBEP)'lerin ne tür avantaj ve dezavantajlar sağladı̆̆ını karşılaştırarak belirlemektir. Çalışma da betimsel tarama yöntemi kullanılmıştır. Veriler yarı yapılandırılmış görüşme yöntemi ile Erzurum ilinde görev yapan on beş gönüllü ögretmenden elde edilmiştir. Araştırma verileri betimsel analiz yöntemi ile analiz edilmiştir. Araştırma sonunda ögretmenlerin bir birine yakın sayllarda PPBEP ve ÖHBEP kullandiklart belirlenmiştir. Çalışmaya katılan öğretmenler, BEP'lerin içeriğine davranış problemleri ile ilgili bölümün de eklenmesi gerektiğini vurgulamışlardır. Ayrıca öğretmenlerin kullandıkları BEP türleri karşılaştırıldı̆̆ında, ÖHBEP'lerin, PPBEP'lere göre birçok açıdan daha olumlu sonuçlarının olduğunu ancak hazırlamada zaman problemi yaşadıklarını belirtmişlerdir. Çalışma sonuçlarına göre ögretmenlerin zaman problemlerini çözmeye yönelik daha kullanışlı ve daha kolay hazırlanabilen BEP tasarıları yapılmalıdır.

Anahtar Kelimeler: Bireyselleştirilmiş eğitim programı, kaynaştırma, özel eğitim

\section{Investigation of Teachers' Opinions on IEP Applications in Preparing Individualized Education Program (IEP) Process}

\section{Abstract}

This study aims to determine the advantages and disadvantages of the Package Program IEP (PPIEP) teachers use and the IEPs Prepared by Teachers (IEPPbT) by comparing them. Data were collected from fifteen volunteer teachers working in Erzurum through semistructured interview technique and analyzed through descriptive analysis. At the end of the study it was found that teachers use PPIEP and IEPbT almost at the same rate. Teachers participating the study emphasized that a section regarding behavioral problems must be added to the IEPs. Furthermore, when the IEP types that teachers use were compared, they stated that IEPPbT had more positive aspects than PPIEP, but they had time problems while preparing those. As a result, IEP drafts that are more useful and easier to prepare must be prepared to solve the time problem of teachers.

\footnotetext{
* Necmettin Erbakan Üniversitesi, Eğitim Fakültesi, Özel Eğitim Bölümü, Konya, Türkiye, senayilik@gmail.com, ORCID: 0000-0001-7092-379X iD

** Necmettin Erbakan Üniversitesi, Eğitim Fakültesi, Özel Eğitim Bölümü, Konya, Türkiye, yunusemregunay@gmail.com, ORCID: 0000-0003-3326-2579
}

Kaynak Gösterme: İlik, Ş. Ş. \& Günay, Y. E. (2020). Bireyselleştirilmiş eğitim programı (bep) hazırlama sürecinde tercih edilen bep uygulamaları üzerine öğretmenlerin görüşlerinin incelenmesi. Bayburt Eğitim Fakültesi Dergisi, 15(30), 347-362. https://doi.org/10.35675/befdergi.728139 
Keywords: Individualized education program, mainstreaming, special education,

\section{Giriş}

Günümüzde öğrencilerin çeşitli alanlarda yeteneklerinin var olması düşüncesinin önemli hale gelmesiyle özel gereksinimli öğrencilerin eğitimine verilen değer de artırmıştır. Öğrencilerin kimi alanlarda yetersiz olması, öğrencinin bütün alanlarda başarılı olamayacağı anlamına gelmemektedir (Fiscus \& Mandell, 2002). Bu düşünce noktasından hareketle özel eğitimin temel amacını, öğrencinin potansiyellerini ortaya çıkartıp, bu potansiyelleri en üst noktada kullanabilmelerine firsat verilmesi, öğrencinin kendi kendine yeten, çevreye uyum sağlayan, faydalı ve üreten bireyler olabilmeleri şeklinde tanımlanmıştır (Ataman, 2009).

Her ferdin bedensel özellikleri, zekâ seviyesi, yetenekleri, ilgi duyduğu alanlar, duygu ve düşünce yapısı birbirinden farklılıklar göstermektedir. Eğitimde fertlerde ki bu bireysel farklılıklara uygun olarak düzenlenmesi fikri kabul görmektedir (Arivett, Rust, Brissie \& Dansby, 2007). Dolayısıyla, öğrencilere öğretilecek bilgi ve becerilerin, ortamlara, koşullara, zamana ve öğrencilerin bireysel farklılıklarına uygun olarak yapılandırılması gereklidir. Bu yapılandırmalar, aynı şekilde özel gereksinimli öğrencilerin eğitimlerinde kullanılan Bireyselleştirilmiş Eğitim Programı (BEP)'in hazırlanması gerektiğini de ortaya koymuştur. Fisscuss ve Mandell'e (2002) göre, özel gereksinimli öğrencilerin eğitsel ihtiyaçlarını karşılayabilmek ve planlayabilmek ancak BEP çalışmaları ile mümkündür (Avcioğlu, 2011).

BEP öğrencilerin ihtiyaçları, gereksinimleri üzerine hazırlanan özel gereksinimli öğrencilere özel olarak hazırlanan bir programdır (Kamens, 2004). Özel gereksinimli tüm öğrenciler için eğitime en uygun öğrenme ortamlarını ve gelişim düzeylerini artırmayı sağlamak için önemli bir araçtır (Smith \& Brownell, 1995). Aynı zamanda öğrenciye eğitimi boyunca rehberlik eden, gelişim alanlarına uygun, öğrencinin var olan ihtiyaçlarının karşılanmasını sağlayan yazılı bir dokümandır (Smith \& Brownell, 1995).

BEP; özel eğitime gereksinimi olan bireylerin gelişim özellikleri, eğitim performansları ve ihtiyaçları doğrultusunda hedeflenen amaçlara yönelik hazırlanan ve bireylere verilecek destek eğitim hizmetlerini de içeren özel eğitim programı olarak ifade edilmiştir. Özel Eğitim Hizmetleri Yönetmeliği (2018), özel gereksinimi tanılanmış öğrenci için BEP' in ders yılı başında tamamlanmış olmasını zorunlu hale getirmiştir. Her BEP, en azından yılda bir kez değerlendirilmesi zorunludur. Bu değerlendirmeler ile çocuk hakkında programında değişiklik gerektirip gerektirmediği belirlenmelidir. BEP hazırlama uygulama ve değerlendirme süreci BEP ekibi tarafından yapılmaktadır. BEP ekibi içerisinde, okul müdür ya da müdür yardımcısı, özel eğitim öğretmeni, rehber öğretmen, sınıf öğretmeni, aile ve gerekli görüldüğünde çocuğun eğitim ve gelişiminden sorumlu uzmanlar yer almalıdır. $\mathrm{Bu}$ 
ekip kendi uzmanlık alanları doğrultusunda öğrencinin bir yıl boyunca kullanacağı programı hazırlamak ve değerlendirmek ile sorumludur.

BEP hizmet alan öğrenciler ile hizmet veren öğretmenler arasında yapılan bir anlaşma niteliğindedir. Hizmet verenler, öğretmenler ve özel gereksinimli öğrencilerin eğitiminden sorumlu tüm personel, hizmet alanlar ise özel gereksinimli öğrencilerin ve ailesidir. Bu durumda BEP hizmet verenler ve hizmet alanların ortak bir ürünü olmalıdır. Tüm bunlarla birlikte BEP' in özel gereksinimli tüm çocuklar için hazırlanması yasal bir zorunluluktur (Kargın, 2007).

Özel eğitim alanı içinde görev yapan öğretmenlerden belli yeterliliklere sahip olmaları beklenmektedir. Bu yeterliliklerin içinde en önemli olanlardan birisi de BEP geliştirebilmeleri ve geliştirilen BEP'in içinde çeşitli değerlendirme stratejilerini kullanabilmeleridir (Christle \& Yell, 2010). BEP'in uygulanmasında önemli bir rolü olan öğretmenlerin BEP' in hazırlanması ve uygulanması ile ilgili bilgi düzeyleri ve tutumları özel gereksinimli öğrencilerin eğitimlerini doğrudan etkilemektedir (Avcıŏglu, 2011).

Alan yazın incelendiğinde BEP ile ilgili çalışmalara rastlanmaktadır. Yapılan çalışmalar BEP kullanım ve hazırlama yetersizlikleri ile alakalı olduğu ve öğretmenlerin BEP hazırlama konusunda eksikliklerinin olduğunu göstermektedir (Arivett, Rust, Brissie \& Dansby, 2007; Christle \& Yell, 2010; İlik, 2018; Kosko \& Wilkins, 2009; Nizamoğlu, 2006; Öztürk ve Eratay, 2010; Tike, 2007). BEP hazırlama konusunda yetersizlikleri, eğitim eksikliği ile ilişkilendiren (Çuhadar, 2006; Küçüker, Kargın \& Akçamete, 2002; Lee-Tarver, 2006; Lytle \& Bordin, 2001; İlik \& Sarı, 2017; Yıkmış \& Bahar, 2002), zaman yetersizliği ile ilişkilendiren (Johns, Crowley \& Guetzloe, 2002) çalışmalara rastlanmaktadır. Bu çalışmada ise özel eğitim alanında çalışan öğretmenlerin kullandığı, Paket Program BEP (PPBEP) ve Öğretmenlerin Hazırladığı BEP (ÖHBEP)' lerin ne tür avantaj ve dezavantajlar sağladığı, öğrencilerin ihtiyaçlarına ne düzeyde cevap verdiği belirlenmiştir.

\section{Yöntem}

\section{Araştırma modeli}

$\mathrm{Bu}$ çalışmada özel gereksinimli öğrencilerin eğitiminden sorumlu olan öğretmenlerin kullandıkları BEP ile ilgili görüşlerini belirlemek ve derinlemesine inceleme yapmak amaciyla nitel araştırma yöntemlerinden betimsel tarama modeli kullanılmıştır. Yıldırım ve Şimşek’e (2003) göre, betimsel tarama bir durum ile ilgili bireylerin bakış açılarından görebilmeye ve bu bakış açılarını oluşturan sosyal yapıyı ortaya koymaya imkân tanımaktadır.

\section{Çalışma Grubu}

Araştırmaya katılan grup Erzurum ilinde MEB' e bağlı okullarda görev yapan 15 gönüllü öğretmenlerden oluşmaktadır. Öğretmenler, özel eğitim öğretmenleri ve 
kaynaştırma öğrencisi bulunan sınıflardaki sınıf öğretmenleridir. Çalışma süreci öğretmenlere anlatılarak katılıp katılmayacakları sorulduktan sonra katılmak isteyen öğretmenler araştırmaya dahil edilmiştir. Bu grup hem özel eğitim öğretmenlerinden hem de kaynaştırma öğrencisine destek eğitim veren birinci kademe sınıf öğretmenlerinden oluşmaktadır. Öğretmenler ile ilgili demografik bilgiler Tablo 1' de verilmiştir.

Tablo 1.

Ögretmenlerin Demografik Özellikleri

\begin{tabular}{llll} 
& & $\mathbf{f}$ & $\mathbf{\%}$ \\
\hline \multirow{2}{*}{ Cinsiyet } & Kadın & 7 & 46,6 \\
\cline { 2 - 4 } & Erkek & 8 & 53.3 \\
\hline \multirow{2}{*}{$\begin{array}{l}\text { BEP kullanma } \\
\text { durumları }\end{array}$} & Evet & 15 & 100 \\
\cline { 2 - 4 } $\begin{array}{l}\text { Meslekte } \\
\text { çalışma yılı }\end{array}$ & Hayır & 0 & 0 \\
\cline { 2 - 4 } & $6-10$ & 7 & 46.6 \\
\hline \multirow{2}{*}{ Branş } & $11-15$ & 5 & 33.3 \\
\cline { 2 - 4 } & Özel eğitim öğretmeni & 10 & 20 \\
\cline { 2 - 4 } & Sinıf öğretmeni & 5 & 33.3 \\
\hline
\end{tabular}

\section{Veri Toplama Aracı}

Çalışmada veriler nitel araştırma yönteminde kullanılan yarı yapılandırılmış görüşme formu ile elde edilmiştir. Yarı yapılandırılmış görüşme, araştırma probleminin boyutlarının tümünü gerçekleştiren bir yöntemdir (Yıldırım \& Şimşek, 2003).

Yarı Yapılandırılmış Görüşme Formun geliştirilmesi aşamasında alanyazın taranmıştır. Daha sonra alanyazından elde edilen bilgiler doğrultusunda on soruluk taslak form hazırlanmıştır (Avcıoğlu, 2011; İlik \& Sarı, 2017; Yıkmış \& Bahar, 2002). Taslak formunun iç geçerliğini sağlamak için özel eğitim alanında uzman üç akademisyenin görüşü alınmıştır. Formdaki bazı soruların benzer durumları ölçebileceğine yönelik önerileri doğrultusunda yedi soruluk taslak görüşme formu elde edilmiştir. Son şekli verilen Yarı Yapılandırılmış Görüşme Formundaki sorular pilot çalışmada uygulanmıştır. Pilot uygulamaya katılan öğretmenlerin görüşleri doğrultusunda pilot uygulamada kullanıldığı haliyle Yarı Yapılandırılmış Görüşme Formları araştırmada kullanılmıştır. Görüşmeler ortalama $20 \mathrm{dk}$ sürmüştür.

1. BEP hazırlama sürecinde performans alımını ne kadar sürede yapıyorsunuz? Gerekçelerini açıklayınız.

2. Kullandığınız BEP'i kendiniz mi hazırladınız yoksa PPBEP mi kullandınız? Gerekçelerini açıklayınız.

3. Kullandığınız BEP'in öğrencilerin ihtiyaçlarına cevap verdiğini düşünüyor musunuz? Hangi ihtiyaçlara cevap verdiğini açıklayınız. 
4. Kendi hazırladığınız BEP ile hazır indirilen bir BEP arasında farklılıklar olacağını düşünüyor musunuz? Bu farklılıkları açıklayınız.

5. Sizden hazırlamanız istenilen BEP te hangi bölümü gereksiz buluyorsunuz?

6. Size göre BEP' te başka bir bölüm olmalı mı? Hangi bölüm olsa daha kullanışlı olur açıklayınız.

7. Hazırladığınız BEP’ teki yılsonuna kadar tamamlanması gereken hedeflere ulaşıyor musunuz?

\section{Verilerin Analizi}

Araştırmada elde edilen nitel veriler nitel analiz yöntemlerinden olan betimsel analiz yöntemi ile analiz edilmiştir. Betimsel analiz, verilerin araştırma sorularının ortaya koyduğu temalara göre organize edilmesine ve görüşmede kullanılan sorular veya boyutlar dikkate alınarak sunulmasına imkân vermektedir (Yıldırım \& Şimşek, 2003). Öğretmenler ile gerçekleştirilen görüşmeler ses kayıt cihazı ile kaydedilmiştir. Görüşmeler tamamlandıktan sonra, görüşme kayıtlarında hiçbir değişiklik yapılmadan veriler yazılı metne dönüştürülmüştür. Görüşmeye katılan her bir katılımcı için yazılı hale getirilen görüşmeler araştırmacılar tarafindan tek tek ele alınarak değerlendirilmiştir. Her bir madde bulgular doğrultusunda alt gruplara ayrılmıştır. Her bir madde önce araştırmacılar tarafindan bağımsız olarak alt gruplara ayrılmıştır. Bulgular araştırmacılar tarafından önce birbirinden bağımsız olarak oluşturulmuş sonra elde edilen bulgular karşılaştırılması yapılmıștır. Görüşleri aynen aktarılan öğretmenler, sırasıyla Ö.1,Ö.2, Ö.3, .. ş şeklinde sembolize edilmiştir.

\section{Bulgular}

$\mathrm{Bu}$ bölümde öğretmenlerden elde edilen veriler doğrultusunda frekanslara ve doğrudan alıntılara yer verilmiştir.

Tablo 2.

"BEP hazırlama sürecinde performans alımını ne kadar sürede yapıyorsunuz? Gerekçelerini açıklayınız.” Sorusuna ilişkin bulgular

\begin{tabular}{ll}
\hline Hazırlama Süresi & f \\
\hline 1 Hafta & 3 \\
\hline 2 Hafta & 5 \\
\hline 3 Hafta & 7 \\
\hline
\end{tabular}

"BEP hazırlama sürecinde performans alımını ne kadar sürede yapıyorsunuz? Gerekçelerini açıklayınız." kategorisinde sorulan soruya, görüşme yapılan öğretmenlerden 3'ü BEP hazırlama sürecinde yapılan performans alımı süresinin 1 haftayı geçmediğini söylemiştir. Görüşme yapılan 5 öğretmen performans alımını PPBEP hazırladıkları için 2 hafta da yaptıklarını söylemişlerdir. 7 öğretmen ise BEP 
hazırlama sürecinde performans alımını resmi tarihine uyduğunu ve 3 haftada yaptığını belirtmiştir.

"Uzun süredir bu işi yapıyorum ve bu tecrübe süreci daha iyi yönetmemi sağlıyor. Bir hafta içerisinde performans alımını bitiriyorum" (Ö.2)

"Öğrencide problem davranış varsa bu problem davranışı gözlemede 2 haftalık süre yeterli oluyor”.(Ö.8)

"Sene başı zümre kurulunda üç haftalık süreye karar veriyoruz ve uymam gerekiyor"(Ö.10)

"Yasal sürenin 3 hafta ve öğrenciyi tanıma da bu süre çok önemli, genellikle yeterli oluyor"(Ö.5)

"Öğrencilerin o an ki fiziksel ihtiyaçları ve ortamın her an uygun olmayışından dolayı 3 hafta da daha doğru sonuçlar alıyorum”(Ö.1)

Tablo 3 te Öğretmenlerin farklı BEP kullanma durumlarına ilişkin bulgulara yer verilmiştir.

Tablo 3.

"Kullandığınız BEP'i kendiniz mi hazırladınız yoksa PPBEP mi kullandınız? Gerekçelerini açıklayınız. ” Sorusuna ilişkin bulgular

\begin{tabular}{ll}
\hline Kullanılan BEP Türü & f \\
\hline Kendim hazırladım. & 8 \\
\hline Hazır BEP programı kullandım. & 5 \\
\hline $\begin{array}{l}\text { Temel dersleri (Türkçe, matematik, sosyal bilimler ve fen bilimleri) } \\
\text { kendim hazırladım. Diğer dersler için program kullandım. }\end{array}$ & 2 \\
\hline
\end{tabular}

Tablo 3' te görüldüğü üzere, "Kullandığınız BEP'i kendiniz mi hazırladınız yoksa PPBEP mi kullandınız? Gerekçelerini açıklayınız." Kategorisinde ki soruya araştırmaya katılan 8 öğretmen BEP'i kendisinin hazırladığını söylemişlerdir. Öğretmenler öğrencinin ihtiyaçlarına hazır BEP programlarının tam olarak cevap vermeyeceğini belirtmişlerdir. Araştırmaya katılan 5 öğretmen hazır BEP programı kullandığını bunun en önemli nedeninin zaman yetersizliği olduğunu söylemişlerdir. Araştırmaya katılan 2 öğretmen temel dersleri (Türkçe, matematik, sosyal bilimler ve fen bilimleri) kendim hazırladıklarını diğer dersler için BEP hazırlama programı kullandığını söylemiştir.

"Her özel eğitim öğretmeninin öğrencisine en uygun amaçları seçmesi için BEP'i kendisinin hazırlaması gerekiyor. Bende bu nedenle kendim hazırlıyorum.”(Ö.5)

"Hazır BEP kullanıyorum çünkü daha hızlı bir şekilde BEP'i elde ediyorum ve bütün amaçlar hazır BEP programlarında var”(Ö.3) 
"BEP hazırlama konusunda tam bilgiye sahip değilim, özel eğitim alanına alan dışı geçiş yaptım. Bu nedenle hazır BEP kullanmak zorunda kalıyorum." (Ö.6)

Tablo 4' te Öğretmenlerin kullandıkları BEP'in öğrencilerin ihtiyaçlarına cevap verme durumuna ilişkin bulgulara yer verilmiştir.

Tablo 4.

“Kullandı̆̆ınız BEP’in öğrencilerin ihtiyaçlarına cevap verdiğini düşünüyor musunuz? Hangi ihtiyaçlara cevap verdiğini açıklayınız.” Sorusuna ilişkin bulgular

\begin{tabular}{lll}
\hline İhtiyaçları Karşılama & & $\mathbf{f}$ \\
\hline \multirow{2}{*}{ BEP Hazırlayan } & Öğrencinin ihtiyacına cevap veriyor. & 8 \\
\cline { 2 - 3 } & Öğrencinin ihtiyaçlarına cevap vermiyor. & 2 \\
\hline \multirow{2}{*}{ Hazır BEP Kullanan } & Öğrencinin ihtiyaçlarına cevap veriyor. & 1 \\
\cline { 2 - 3 } & Kısmen cevap veriyor. & 3 \\
\cline { 2 - 3 } & Öğrencinin ihtiyaçlarına cevap vermiyor. & 1 \\
\hline
\end{tabular}

Tablo 4' te görüldüğü üzere “Kullandığınız BEP'in öğrencilerin ihtiyaçlarına cevap verdiğini düşünüyor musunuz? Hangi ihtiyaçlara cevap verdiğini açıklayınız?" kategorisinde ki soruya BEP hazırlayan 11 öğretmen kullandığ BEP'in öğrencinin bütün ihtiyaçlarına cevap verdiğini söylemiştir. Hazır BEP kullanan1 öğretmen kullandığı BEP'in öğrencinin ihtiyaçlarına cevap verdiğini söylerken, 1 öğretmen ise BEP'in öğrencinin ihtiyaçlarına cevap vermediğini formaliteden ibaret olduğunu belirtmiştir. Hazır BEP kullanan 3 öğretmen kullandıkları BEP'in öğrenciyi tamamen geliştirebilecek özellikte olmadığını öğrencinin ihtiyaçlarını kısmen karşıladığını söylemiştir.

"Kullandığım BEP öğrencinin toplumsal uyum, öz bakım ve akademik becerilerine önemli katkılar yapıyor. Çünkü bunların hepsini birebir gözlem ile elde ettim." (Ö.8)

"Sene içinde öğrencilerimin okula devam sürelerinin az olması durumunda bütün ihtiyaçlara cevap verecek bir BEP hazırlayıp, revize etmemi engelliyor. Yani çocuğa uygun hazırlanıyor fakat süreç içerisinde BEP kullanılmaz hale geliyor."(Ö.10)

"Sene içinde ortaya çıkan yeni problem davranışlar BEP'in amaçlarını uygulamayı sekteye uğratıyor.”(Ö.14)

"Çocuğun ihtiyaçlarını belirlerken hazır BEP formatına bağlı kalmak, çocuğa özgü ihtiyaçları ya da benim özgün çözüm önerilerimi yansıtamıyorum. Bu da gerçek duruma uymayan bir kâğıt parçasına dönüşüyor.”(Ö.6)

Tablo 5'te Öğretmenlerin kendi hazırladıkları BEP ile PPBEP arasında ki farklılıklara ilişkin bulgulara yer verilmiştir. 
Tablo 5 .

"Kendi hazırladığııız BEP ile hazır indirilen bir BEP arasında farklılıklar olacă̆ını düşünüyor musunuz? Bu farklılıkları açıklayınız. ”Sorusuna ilişkin bulgular

\begin{tabular}{llll}
\hline Türler Arası Fark & & F \\
\hline BEP & $\begin{array}{l}\text { Öğrenci ihtiyaçlarına cevap vermesi konusunda } \\
\text { Hazırlayanlar }\end{array}$ & 4 \\
& farklılıklar var. & \\
\cline { 2 - 3 } & Kendi hazırladığım BEP' te esneklik yapabiliyorum & 4 \\
\cline { 2 - 3 } & $\begin{array}{l}\text { Hazır BEP programları işitme engelli öğrenciler için } \\
\text { yetersiz kalıyor }\end{array}$ & 1 \\
\cline { 2 - 3 } & $\begin{array}{l}\text { Detayların açıklanmasında hazır BEP programları } \\
\text { yeterli olmuyor }\end{array}$ & 1 \\
\hline Hazır & BEP & Farklılık olduğunu düşünmüyorum. & 3 \\
\cline { 2 - 4 } Kullananlar & $\begin{array}{l}\text { Detayların açılanmasında hazır BEP programları bazı } \\
\text { noktalarda yeterli olmuyor }\end{array}$ & 2 \\
\hline
\end{tabular}

Tablo 5' te görüldüğü üzere, “ÖHBEP ile PPBEP arasında farklılıklar olacağını düşünüyor musunuz? Bu farklılıkları açıklayınız”. BEP hazırlayan 10 öğretmen ve hazır BEP kullanan 1 öğretmen kendi hazırladığı BEP ile hazır BEP arasında farklılıklar olduğunu düşünmektedir. Kendi hazırladığ1 BEP'in öğrencinin bireysel farklılıklarını tam olarak yansıttığını söylemişlerdir. BEP uygulamalarından hazır olarak indirilen taslakların kendi hazırlayacağı BEP ile farklı yönlerinin olmadığını 3 öğretmen söylemiştir.

“İ̧sitme engelli öğrenciler için hazırlanan BEP'in hazır bir şekilde indirerek kullanmanın öğretimi olumsuz yönde etkiler ve öğrenciyle başarı elde edemem."(Ö.4)

"Hazır olarak indirilen BEP'in öğrencinin ihtiyaçlarına uymuyor ve içinde beceri analizi konusunda bilgiler yer almıyor.”(Ö.2)

"Amaçların hepsi programda hazır bir şekilde var ve tek tek kendim seçebiliyorum. Bu yüzden farklılık olduğunu düşünmüyorum.”(Ö.13)

"Öğrenci ihtiyaçlarına cevap vermede farklılıklar olabiliyor ama BEP hazırlama konusunda yeterli bilgiye sahip değilim. Bu nedenle hazır BEP kullanıyorum.”(Ö.12)

Tablo 6' da Öğretmenlerin BEP bölümlerini karşılaştırmalarına ilişkin bulgulara yer verilmiştir.

Tablo 6.

"Sizden hazırlamanız istenilen BEP te hangi bölümü gereksiz buluyorsunuz?" Sorusuna ilişkin bulgular

\begin{tabular}{lll}
\hline Gereksiz Bölüm & f \\
\hline \multirow{2}{*}{$\begin{array}{l}\text { BEP } \\
\text { hazırlayan }\end{array}$} & Gereksiz bulduğum bölüm yok. & 8 \\
\cline { 2 - 3 } & Veliler ile iş birliği yapmayı gereksiz buluyorum. & 2 \\
\hline
\end{tabular}




\begin{tabular}{llll}
\hline Hazır BEP & \multicolumn{2}{l}{ Veliler ile iş birliği yapmayı gereksiz buluyorum. } & 1 \\
\cline { 2 - 3 } kullanan & $\begin{array}{l}\text { Öğrencinin yapabildiklerini yazmayı gereksiz } \\
\text { buluyorum. }\end{array}$ & 2 \\
\cline { 2 - 3 } & $\begin{array}{l}\text { Kullanılacak yöntem ve materyalleri yazmayı gereksiz } \\
\text { buluyorum. }\end{array}$ & 1 \\
\cline { 2 - 3 } & Gereksiz bulduğum bölüm yok. & 1 \\
\hline
\end{tabular}

Tablo 6' da görüldüğü üzere, Sizden hazırlamanız istenilen BEP te hangi bölümü gereksiz buluyorsunuz? Kategorisinde ki soruya araştırmaya katılan 15 öğretmenden çoğunluğu BEP'te gereksiz bir bölüm görmediğini söylemiştir. BEP hazırlayan 10 öğretmen BEP'te gereksiz bir bölüm olmadığını ve yeni noktalar eklenmesi gerektiğini söylemiştir. Hazır BEP kullanan 4 öğretmen gereksiz bulduğumu bölümler olduğunu söylemiştir. Hazır BEP kullanan 1 öğretmen gereksiz bulduğu bir bölüm olmadığını söylemiştir.

\begin{abstract}
"Velileri BEP hazırlama sürecine dâhil ettiğimde öğrenciyle o eğitim öğretim yılında ulaşamayacağım hedeflerin yazılmasını istiyorlar. Bu durum sağlıklı bir BEP hazırlamama engel oluyor. Sağlıklı BEP hazırlamak için veliler ile amaçlar konusunda çok iletişim kurulmaması gerektiğini düşünüyorum.”(Ö.8)

“Öğrencinin yapabildiklerini yazmaya gereksiz buluyorum. Çünkü amaçların başladığı yerden bir önceki amaç öğrencinin yapabildiği son durumdur ve son amaçtan önceki amaçlar yapabildiklerini oluşturur bu yüzden baştan yazmaya gerek yok."(Ö.10)
\end{abstract}

Tablo 7' de Öğretmenlerin BEP'te ilave edilme gerekliliğine ilişkin bulgulara yer verilmişstir.

Tablo 7.

“Size göre BEP' te başka bir bölüm olmalı mı? Hangi bölüm olsa daha kullanışlı olur açıklayınız." Sorusuna ilişkin bulgular

\begin{tabular}{|c|c|c|}
\hline \multicolumn{2}{|l|}{ Önerilen Ekleme } & f \\
\hline \multirow[t]{3}{*}{ BEP hazırlayan } & Şimdiki haliyle yeterli & 5 \\
\hline & Problem Davranışların yazılacağı bir bölüm olmalı & 3 \\
\hline & Kişisel bilgiler kısmı daha ayrıntılı olmalı & 2 \\
\hline \multirow{2}{*}{$\begin{array}{ll}\text { Hazır } \\
\text { kullanan }\end{array}$} & Şimdiki haliyle yeterli & 3 \\
\hline & Problem Davranışların yazılacağı bir bölüm olmalı & 2 \\
\hline
\end{tabular}

Tablo 7' de görüldüğü üzere Size göre BEP'te başka bir bölüm olmalı mı? Hangi bölüm olsa daha kullanışlı olur açıklayınız. Kategorisinde ki soruya araştırmaya katılan öğretmenlerden 5'i hazır BEP kullanan 5'i BEP hazırlayan 10 öğretmen BEP'in şu an ki halinin yeterli olduğunu ve kullanışlı olduğunu belirtmiştir. Herhangi bir ekleme yapılmadan da işlevsel bir şekilde kullanılabileceğini söylemiştir. BEP hazırlayan 5 öğretmen ise bazı noktalarda eklemeler yapılmasının daha iyi olacağını söylemişlerdir. 
"BEP'in içinde davranışları yazacak bir bölüm yok ve bu durum öğrencinin davranışlarını kayıt altına almayı zorlaştırıyor. BEP'in içinde böyle bir bölüm olmasının davranışların değişiminin gözlenmesi açısından daha faydalı olacağını düşünüyorum.'”(Ö.5)

"BEP'in içinde yer alan kişisel bilgiler kısmı daha ayrıntılı olmalıdır. Öğrenciyi daha yakından tanımak eğitimi sürecine olumlu katkılar sağlayacaktır.”(Ö.8)

Tablo 8'de Öğretmenlerin BEP'te hedeflere ulaşma durumlarına ilişkin bulgulara yer verilmiştir.

Tablo 8.

"Hazırladığınız BEP' teki yılsonuna kadar tamamlanmast gereken hedeflere ulaşıyor musunuz?” Sorusuna ilişkin bulgular

\begin{tabular}{lll}
\hline Yılsonu Hedeflerine Ulaşım & f \\
\hline \multirow{2}{*}{ BEP Hazırlayan } & Bütün amaçlara ulaşıyorum. & 6 \\
\cline { 2 - 3 } & Yarı yarıya ulaşıyorum. & 4 \\
\hline \multirow{2}{*}{ Hazır BEP kullanan } & Bütün amaçlara ulaşıorum. & 1 \\
\cline { 2 - 3 } & Yarı yarıya ulaşıyorum. & 2 \\
\cline { 2 - 3 } & Birçok amaca ulaşamıyorum. & 2 \\
\hline
\end{tabular}

Tablo 8' de görüldüğü üzere, 'Hazırladığınız BEP'te ki yıl sonuna kadar tamamlanması gereken hedeflere ulaşıyor musunuz?" kategorisinde ki soruya araştırmaya katılan öğretmenlerden bütün amaçlara ulaştığını söyleyen öğretmenlerden 6 tanesi BEP'i kendi hazırlayan öğretmenlerdir. Hazır BEP kullanan 1 öğretmen bütün amaçlara ulaştığını söylemiştir. $\mathrm{Bu}$ öğretmenler sene başında performans alımına çok dikkat ettiklerini ve bu doğrultuda doğru amaçları yazıklarını dile getirmişlerdir. BEP hazırlayan 4 öğretmen ise amaçların yarısına ulaştığını söylemiştir. Bu duruma gerekçe olarak sene içinde ortaya çıkan problem davranışların, hasta olma durumlarının amaçlara ulaşmayı zorlaştırdığını söylemişlerdir. Hazır BEP kullanan öğretmenlerden 2 tanesi de amaçların yarısına ulaştıklarını söylemiştir. Hazır BEP kullanan 2 öğretmen birçok amaca ulaşamadığını söylemiştir.

"Öğrencim geçen yıl ameliyat olduğu için okula 3 hafta devam etmedi ve bu durum geçen yıl aldığı amaçlara ulaşmasını güçleştirdi.”(Ö.9)

"Öğrencilerin raporları ağır derece ve sene başında ki davranışları ile yıl içinde ki davranışları çok farklılık gösteriyor. Bu nedenle yazdıkları birçok amaca ulaşamıorum.”(Ö.13)

\section{Tartışma, Sonuç ve Öneriler}

$\mathrm{Bu}$ çalışmada özel gereksinimli öğrencilerin eğitiminden sorumlu olan öğretmenlerin BEP'e ilişkin görüşleri, önerileri ve BEP'i nasıl hazırladıklarına dair 
bilgi toplanması amaçlanmıştır. Araştırma Erzurum ilinde görev yapan özel eğitim öğretmenleri ve kaynaştırma öğrencisi bulunan sınıflardaki sınıf öğretmenleri ile yapılmıştır. Araştırmaya 15 öğretmen katılmıştır. Çalışmaya katılan öğretmenlere BEP kullanıp kullanmadıkları, BEP' i nasıl hazırladıkları, BEP ile ilgili düşünceleri, BEP'te eksik ya da gereksiz buldukları noktalar sorulmuştur.

Çalışma sonuçları incelendiğinde bütün öğretmenlerin BEP kullandıkları ve BEP'i gerekli olduğunu düşündükleri ortaya çıkmıștır. Öğretmenlerin BEP' i gerekli buldukları bulgusunu yapılan çalışmalar desteklemektedir (Lee Tarver 2006; Öztürk, 2009; Bedur, Bilgiç \& Taşlıdere, 2015; Kontaş \& Yağc1, 2016), yapmış oldukları araştırmada öğretmenlerin BEP'i lüzumlu gördüklerini, BEP'in eğitim sürecine dahil olan herkes için faydalı olduğunu belirlemişlerdir. Başka bir çalışmada benzer şekilde BEP' in faydalı olduğu öğretmenler tarafindan belirtilirken, programın hazırlanmasının oldukça fazla zamanlarını aldığı öğretmenlerin çoğunluğu tarafindan vurgulanmıştır (Öztürk, 2009)

Öğretmenlerin performans alımına ilişkin belirttikleri süreler incelenmiş ve yasal süre olan 3 haftaya kaç öğretmenin uyduğu belirlenmiştir. Araştırmaya göre öğretmenlerin BEP'in yasal süreç hakkındaki bilgilerinde eksiklikler olduğu belirlenmiştir. Bir hafta gibi kısa bir sürede BEP i hazırladıklarını belirten öğretmenlerin olması, bu durumun ilerleyen aşamalarda olumsuz olarak yansıyacağını düşündürtmektedir.

Öğretmenlerin hazır BEP kullanmadaki nedenleri sorulduğunda öğretmenler zaman yetersizliğini özellikle belirtmişlerdir. Çalışmamızın sonucu ile benzerlik gösteren Menlove, Hudson \& Süter'in (2001) çalışması öğretmenlerin BEP hazırlamak için yeterince zamanlarının olmamasını ve buna bağlı olarak ta özen göstererek BEP hazırlayamadıklarını belirtmişlerdir. Benzer şekilde diğer bir çalışma olan Johns, Crowley ve Guetzloe (2002) öğretmenlerin BEP hazırlamada eksikliklerinin olduğunu ve BEP hazırlamak için yeterince zamanlarının olmadığı yönünde sonuçlar elde etmişlerdir.

Öğretmenlerin BEP te gereksiz bir bölüm olup olmadığına yönelik görüşlerine göre; öğretmenlerin büyük bölümü BEP sürecine ebeveyn katılımını gereksiz gördükleri belirlenmiştir. Öğretmenlerin bu görüşte olmalarının sebebi, bazen aileler BEP hazırlama sürecine bilinçsizce dâhil olduklarında öğretmenlerin işlerini güçleştirdikleri düşünülmektedir. Ancak gerekli düzenlemeler yapıldığı takdirde, ebeveynler; çocuklarını çok iyi tanıdıkları için, çocuklarının eğitimini geliştirmedeki gereklilikleri, çocukların güçlü olduğu durumları, ilgilerinin neler olduğu ve ihtiyaçları hakkında doğru şekilde bilgi verecek kişiler olduğu belirtilmektedir (Avcioğlu, 2011). Öğretmenlerin aileyi sürece dahil etmeme ile ilgili düşünceleri İlik, (2018) çalışmasında da görülmektedir. Bu çalışmada öğretmenlerin BEP hazırlık sürecinde aileleri ile görüşme yaptıklarına dair dokümanlara bakıldığında çalışmaya dahil edilen BEP dokümanların sadece aile görüşme formu kullanma durumlarının \% 50’yi aşmadığı görülmüştür (İlik, 2018). Bu durum çocuklar için 
hazırlanacak olan BEP' lerin, ihtiyaca cevap vermeyeceği ve işlevsel olamayacağ 1 endişesini oluşturmaktadır. Araştırmalar ebeveynlerin çocuklarını çok iyi tanıdıkları için, çocuklarının eğitimini geliştirmedeki gereklilikleri, çocukların güçlü olduğu durumları, ilgilerinin neler olduğu ve ihtiyaçları hakkında doğru şekilde bilgi verecek kişiler olduğu belirtilmektedir (Avcıŏglu, 2011; Billingsley, 1984; Lynch \& Beare, 1990; Hunt, Goetz \& Anderson,1986).

Öğretmenlerin BEP’te eksik bulduğu noktalar sorusuna verilen yanitlar incelendiğinde, öğretmenlerin bir bölümü bu halinin yeterli olduğunu belirtmelerine rağmen bir kısmı da özellikle davranış bozuklukları ile ilgili bir bölümün yer alması gerektiğini ve öğrenciyi tanıma bölümünün daha ayrıntılı olması gerektiğini bildirmişlerdir. Öğretmenlerin davranış bölümü ile alakalı görüşleri pratikte pek çok kolaylık sağlayacağ düşünülmektedir. Özel gereksinimli öğrencilerin büyük çoğunluğunda davranış problemlerinin görülmesi çoğu zaman akademik gelişimin önünde önemli bir engel haline gelebilmektedir. BEP esnek bir program olmasına karşın BEP taslaklarında davranış problemleri ile alakalı bölümlerinin olmamış olmasından dolayı öğretmenlerin bu bölümü eklemede çekingen davrandıkları düşünülebilir. Davranış problemi ile ilgili bir bölümün öğretmenin inisyatifine bırakılarak çoğu durumda görmezden gelinmesine yol açmaktadır. Bu durumun görmezden gelinmesi öğrencinin yeni problem davranışları geliştirmesini ve akademik başarısızlıkları beraberinde getirmesi kaçınılmaz hale gelmektedir. Christle ve Yell (2010) 'Bireyselleştirilmiş Eğitim Programları: yasal gereksinim ve araştırma bulguları' çalışmasında birçok sayıda araştırma incelemiş ve BEP te karşılaşılan güçlükleri ve nitelikli bir BEP te bulunması gerekenleri ortaya koymuşlardır.

Araştırma sonucunda elde edilen bilgiler ışı̆̆ında bazı önerilerde bulunulabilir. Araştırmamız Erzurum ilinde ve 15 öğretmen ile sınırlı olması nedeniyle benzer çalışmaların ülkemizin farklı bölgelerinde daha fazla sayıda öğretmenin katılımıyla tekrarlanmalıdır. Ayrıca öğretmenlerin BEP hazırlama sürecinde ki bilgilerini artırıcı hizmet içi eğitimler düzenlenmelidir. Ailelerin BEP hazırlama sürecine nasıl dahil olacakları konusunda eğitimler verilmeli ve eğitim verilen aileler ile eğitim verilmeyen ailelerin BEP sürecine katılımları ile ilgili performansları değerlendirilebilir.

Araştırma sonucunda öğretmenlerin zaman problemlerini olduğu belirlenmiş olup, zaman problemlerini çözmeye yönelik daha kullanışlı ve daha kolay hazırlanabilen BEP tasarıları yapılmalıdır. BEP'te davranış değerlendirme boyutu ile ilgili bir bölümün eklenmesi üzerine çalışmalar yapılmalıdır. Öğretmenlerin BEP hazırlama sürecinde ki bilgilerini artırıcı hizmet içi eğitimler düzenlenmelidir.

\section{Etik Beyan}

Çalışma verileri, 2018 güz döneminde araştırmaya katılmaya gönüllü öğretmenlerden elde edilmiştir. Çalışma içinde sunulan veriler akademik ve etik 
kurallara uygundur. Tüm değerlendirme ve sonuçları bilimsel etik ve ahlak kurallarına uygun olarak sunulmuştur.

\section{Kaynakça}

Arivett, D.L., Rust, J.O., Brissie, J.S., \& Dansby, V.S. (2007). Special education teachers' perceptions of schoolpsychologists in the context of individualized education program meetings. Education, 127(3), 378-388.

Ataman, A. (2009). Özel eğitim alanı: Özel gereksinimli çocuklar ve özel eğitime giriş. Ankara: Gündüz Eğitim ve Yayıncılık.

Avcıoğlu, H. (2011). Zihin engelliler sınıf öğretmenlerinin bireyselleştirilmiş eğitim programı (BEP) hazırlamaya ilişkin görüşleri. Ankara Üniversitesi Eğitim Bilimleri Fakültesi Özel Eğitim Dergisi, 12(1), 39-53.

Bedur, S., Bilgiç, N., \& Taşlıdere E. (2015). Özel (Üstün) yetenekli öğrencilere sunulan destek eğitim hizmetlerinin değerlendirilmesi, Hasan Ali Yücel Eğitim Fakültesi Dergisi, 12(23), 159-175.

Billingsley, E. F. (1984). Where are the generalized out comes? (An examination of instructional objectives). The Journal of the Association for Persons with Severe Handicaps, 9, 182-192.

Christle, C.A., \& Yell, M. L. (2010). Individualized education programs: Legal requirements and research findings, Exceptionality. 18(3), 109-123.

Fiscus, E.D., \& C.J. Mandell. (2002). Developing individualized education programs, (Editör: Prof. Dr. Gönül Akçamete, Çevirenler: H. G. Şenel, E. Tekin), İstanbul: Seçkin Dağıtım.

Hunt, P., Goetz, L., \& Anderson, J. (1986). The quality of IEP objectives associated with placement on integrated versus segregated school sites. Journal of the Association for Persons with Severe Handicaps, 11(2), 125-130.

İlik, Ş. Ş. (2018). Examination and evaluation of individualized education programs prepared for intellectual disability students, Journal of Human Sciences, 14(4), 4898-4909.

İlik, Ş. Ş., \& Sarı, H. (2017). The training program for individualized education programs (IEPs): Its effect on how inclusive education teachers perceive their competencies in devising IEPs. Educational Sciences: Theory \& Practice, 17(5).

Johns, B. H., Crowley, E. P., \& Guetzloe, E. (2002). Planning the IEP for students with emotional and behavioral disorders. Focus on Exceptional Children, 34(9).

Kamens, M. W. (2004). Learning to write IEPs: A personalized, reflective approach for preservice teachers. Intervention in School and Clinic, 40, 76-80. 
Kargın, T. (2007). Eğitsel değerlendirme ve bireyselleştirilmiş eğitim programı hazırlama süreci. Ankara Üniversitesi Eğitim Bilimleri Fakültesi Özel Ĕ̆itim Dergisi, 8(1), 1-15.

Kontaş, H., \& Yağcı, E. (2016). BİLSEM öğretmenlerinin program geliştirme ihtiyaçlarına ilişkin geliştirilen programın etkililiği. Abant İzzet Baysal Üniversitesi Eğitim Fakültesi Dergisi, 16(3), 902-923.

Kosko, K., \& Wilkins, J.L. (2009). General educators in-service training and their self-perceived ability to adapt instruction for students with IEPs. Professional Educator, 33(2), 1-10.

Lee Tarver, A. (2006). Are individualized education plans a good thing? A survey of teachers' perceptions of the utility of IEPs in regular education settings. Journal of Instructional Psychology, 33(4) 263-272.

Lynch, E. C., \& Beare, P. L. (1990). Thequality of IEP objective sand the irrelevance to instruction for students with mental retardationand behavior disorders. Remedial \& Special Education, 11(2), 48-55.

Menlove, R. R., Hudson, P. J., \& Suter, D. (2001). A field of IEP dreams increasing general education teacher participation in the IEP development process. Teaching Exceptional Children, 33(5), 28-33.

Nizamoğlu, (2006). Sınıf öğretmelerin kaynaştırma ortamlarındaki yeterlilikleri (Yüksek lisans tezi). Bolu, Abant İzzet Baysal Üniversitesi.

Özel Eğitim Hizmetleri Yönetmeliği (2018). Resmi Gazete (Sayı: 30471). Erişim adresi: http://www.resmigazete.gov.tr/eskiler/2018/07/20180707-8.htm

Öztürk, C.C. (2009). Eğitim uygulama okuluna devam eden zihinsel engelli öğrencilerin ögretmenlerinin bireyselleştirilmiş eğitim programı hakkında görüşlerinin belirlenmesi (Yüksek lisans tezi). Bolu, Abant İzzet Baysal Üniversitesi.

Öztürk, C.Ç., \& Eratay, E. (2010). Eğitim uygulama okuluna devam eden zihin engelli öğrencilerin öğretmenlerinin Bireyselleştirilmiş Eğitim Programı hakkında görüşlerinin belirlenmesi. Abant İzzet Baysal Üniversitesi Ĕgitim Fakültesi Dergisi, 10(2), 145-159.

Smith, S.W., \& Brownell, M.T. (1995). Individualized education programs: Considering the broad context for reform, Focus on Exceptional Children, 28(1), 1-12.

Tike, L. (2007). Sinıf öğretmenlerin, rehber öğretmenler ve rehberlik araştırma merkezi çalışanlarının bireyselleştirilmiş eğitim programı hazırlama surecine ilişkin tutumları ve bu süreçte karşılaşstkları güçlüklerin belirlenmesi (Yüksek lisans tezi). Ankara, Ankara Üniversitesi.

Yıkmış, A., \& Bahar, M. (2002) Kaynaştırma sınıflarında çalışan öğretmenlerin kaynaştırma becerilerini gerçekleştirme durumlarının saptanması, Abant İzzet Baysal Üniversitesi Eğitim Fakültesi Dergisi,2(1). 
Yıldırım, A., \& Şimşek, H. (2003) Sosyal bilimlerde nitel araştırma yöntemleri, Ankara: Seçkin Yayınları.

\section{Extended Abstract}

The physical characteristics, intelligence level, abilities, areas of interest, emotion and thought structure of each individual differ from each other. In education, the idea of being arranged in accordance with these individual differences in individuals is accepted. Therefore, the knowledge and skills to be taught to students should be structured the environments, conditions, times and individual differences of the students. These configurations also revealed that the IEP used in the education of students who need special education should be prepared. IEP is an agreement between students who receive service and teachers who provide service. Service teachers are all individuals responsible for the education of individuals with special needs, while those who receive services are the family of the individual with special needs and the individual. Accordingly, IEP is a program that requires all the individuals who are responsible for the education of the individual with special needs to actively participate in the preparation of this program and adopt the determined goals, rather than being a program prepared by a single person. However, IEP is a legal obligation.

When examining the literature of individualized education programs are found in Turkey and their countries related to the IEP studies. Studies show that IEP is related to inadequate use and preparation and teachers do not have sufficient knowledge about preparing IEP (Christle \& Yell, 2010; Çuhadar, 2006; Johns, Crowley \& Guetzloe, 2002; Kosko \& Wilkins, 2009; Küçüker, Kargıı \& Akçamete, 2002; Lee-Tarver, 2006; Lytle \& Bordin, 2001; Nizamoğlu, 2006; Tike, 2007; Destructed \& Spring, 2002; Öztürk \& Eratay, 2010). In this study, it is to make a comparison between the electronic IEPs currently used in many private education institutions and how the IEP applications currently used. Accordingly, it is to determine the level of ready electronic IEP programs used by teachers and to what extent the IEPs currently used respond to the student's needs. It is important because studies related to IEP, which is the main element of private education, have not been conducted in a limited number of electronic IEPs.

In this study, a case study approach was used descriptive scanning method in order to examine the opinions of the teachers involved in the education of students with special needs in order to provide an in-depth study and explain their opinions about IEP. In the study, data were obtained by semi-structured interview method. The group that participated in the study consists of 15 volunteer teachers working in different schools and levels in Erzurum. This group consists of both special education teachers and classroom teachers who support the student with special needs. The data in the study were obtained through a semi-structured interview form used in the qualitative research method. Semi-structured interview is a method developed to ensure that all dimensions and questions related to the research 
problem are covered. During the interview, the interviewer can change the sentence structure and order of the questions, elaborate on some topics, or adopt a more chatstyle method. The qualitative data obtained in the study were analyzed with the descriptive analysis method, which is one of the qualitative analysis methods. After the interviews with the teachers have been completed, the researcher has dumped the data into the interview forms without making any changes in their voice recordings. The written interviews for each participant in the interview were evaluated one by one.

When the study results were examined, it was revealed that all teachers used Individualized Education Program and thought that Individualized Education Program was required. The periods stated by the teachers regarding the performance intake were examined and how many teachers complied with the legal period of 3 weeks. According to the research, it has been determined that there are deficiencies in the knowledge of teachers about the legal requirement of IEP. The teachers, who stated that they prepared IEP in a short period of one week, makes us think that this situation will reflect in the later stages as negativity. When the teachers were asked about the reasons for using the ready IEP, the teachers especially stated the lack of time. They stated that the teachers found that there is a section in IEP that you find unnecessary, that they consider the parental involvement in the IEP process unnecessary. The reason why teachers are in this view is sometimes thought to make teachers' jobs difficult when parents are unconsciously involved in the process. However, if necessary arrangements are made, parents can; As they know their children very well, it is stated that they are the people who will provide accurate information about their needs in developing their education, their strengths, their interests and needs. When the answers given to the question of the points that teachers find missing in the IEP, although some of the teachers stated that this state of affairs was sufficient, some of them stated that there should be a section especially about behavioral disorders and the part of getting to know the student should be more detailed. It is thought that the opinions of the teachers about the behavior section will provide many conveniences in practice. Behavioral problems in the vast majority of students with special needs can often become an important barrier to academic development. However, the absence of such a part in the child's program leads to the discretion of the teacher and in most cases ignores it. Ignoring this situation becomes inevitable for the student to develop new problem behaviors and bring academic failures. In line with the results of this study on IEP applications currently used with the legal IEP, the following recommendations can be made. Inservice trainings should be organized to increase the knowledge of teachers in the IEP preparation process. Programs used in the IEP preparation process should be revised and turned into an area where all teachers can receive information. Studies should be done on adding a section on the behavior assessment dimension in IEP. 